\title{
science \\ Diplomacy in six patterns of reviewers' queries during manuscript revision in scholarly publishing
}

\author{
Jean Iwaz ${ }^{1,2,3,4}$ \\ ${ }^{1}$ Université de Lyon, Lyon; ${ }^{2}$ Université Lyon 1 Claude Bernard, Villeurbanne; ${ }^{3}$ Service de Biostatistique-Bioinformatique, Pôle \\ Santé Publique, Hospices Civils de Lyon, Lyon; ${ }^{4}$ CNRS UMR 5558, Laboratoire de Biométrie et Biologie Évolutive, Équipe \\ Biostatistique-Santé, Villeurbanne, France
}

\section{Introduction}

Background: More often than expected or desired, manuscripts submitted to scientific journals are returned to their authors with the decision "accept after revision" or "revise and resubmit." Obviously, the rate of "revise and resubmit" decisions varies greatly between journals: $25 \%$ for some [1], but $50 \%$ for others [2]. A number of observers have estimated that the actual rate might be much higher, but accurate, documented, and reliable statistics are lacking because of the unknown rate of false new submissions that previously received "revise and resubmit" decisions [3]. Regardless, as previous pointed out, "the probability of a 'revise and resubmit' decision is strongly increasing in the recommendation of any one referee" [4], most likely because "revise and resubmit" decisions help editors delay resolutions of tough cases [3].

The "revise and resubmit" decision upsets most authors because they feel they have to reopen old files and have discussions with unseen meticulous reviewers and editors about unexpected issues regarding a manuscript written months ago. Unless guided by experienced authors, beginners often give in to panic because they feel unable to satisfy all reviewers' requests in the "point-by-point" manner required. They might have read the following by Klingner et al. [5]: "For a 'revise and resubmit' decision to become an acceptance, the revisions must respond constructively to the reviewers' concerns (...). The most certain way to move from the 'accept with revision' category to 'accept' is to make each and every revision requested and then detail how you addressed those revisions in a cover letter that accompanies the resubmission"

Received: September 9, 2021 Accepted: September 29, 2021

Correspondence to Jean Iwaz jean.iwaz@chu-lyon.fr

ORCID

Jean Iwaz

https://orcid.org/0000-0002-5090-8215
[5]. These are certainly wise recommendations and ideal solutions. Nevertheless, because this project appears to be huge, authors might rapidly choose to submit the very same manuscript to another journal in the hope of skipping difficult, unpleasant, or time-consuming tasks, although they know this is never guaranteed; on the contrary, new reviews may come with harsher comments.

Objective: This essay aims to help authors deal diplomatically with six of the most difficult reviewers' queries. 


\section{The Decision to Revise Is Made}

Let us now consider the case where the authors decide to revise their manuscript in accordance with the reviewers' wishes to avoid another lengthy round of peer review and give their manuscript a chance of acceptance in the initial target journal. In that case, most writers who have addressed this topic agree that the authors will have to respond to three categories of reviewers' queries: minor amendments, major revisions, and additional material. Minor amendments and short additions to a manuscript are not problems; they may be made with little effort and within a reasonable amount of time. In my opinion, the major problems stem from three types of comments (ambiguous, contradictory between reviewers, and irrelevant to the topic) and three types of requests for additional material (checks for unlikely sources of bias, pushing the work further, and performing the whole work again on the basis of other hypotheses or with other methods). Fortunately, Klingner et al. [5] added, "You do not necessarily have to make every change suggested."

In 2012, Shaw [6], a previous editor of The Academy of Management Journal, wrote, "The initial submission of a manuscript begins a conversation with reviewers (...). The key, then, is to keep the conversation flowing." Thus, as in any serious and peaceful conversation, diplomacy counts.

\section{Six Patterns of Reviewers' Queries and Authors' Diplomatic Responses}

Here are six examples of when and how diplomacy may prevent conflicts of ideas and rigid positions, instead facilitating concessions and solutions.

\section{Ambiguous comments}

It is certainly puzzling and irritating to read a comment repeatedly without understanding its exact meaning or intention and feel unable to provide an answer. Here, avoid unnecessary stress. Let a colleague read and try to interpret the comment. In most cases, your colleague might find a plausible explanation. If this manoeuver fails, refrain from answering: "I/We did not understand that point." That answer is often sincere but not diplomatic. If sufficient time is available, you may discuss the point with the editor or the associate editor, who would reach out to the reviewer and then get back in touch with you [7]. If a clear answer is not obtained, a helpful strategy is to address the reviewer's comment like: "If you mean X, then...; but, if you mean $\mathrm{Y}$, then..." This demonstrates that you (the authors) have made an effort.

\section{Contradictory comments between reviewers}

This is also bewildering because the authors cannot satisfy two or more reviewers with contradictory answers. Here too, the above referral to the editor remains a valid option [8]. Regardless, an essential point of diplomacy is never to tell a reviewer about the opposite position of another reviewer regarding a specific point. The contrary is objectively and fully logical and, above all, a convenient or expedient easy answer-but definitely not a diplomatic one. Here, instead of exposing the opposition, it is better for the authors to search for and focus on the respective advantages of each position. The answer to each reviewer may come this way: "You pointed out that (...); however, one advantage of our position is that..." or "One opinion is that (...), but we believe that... because..." (see other interesting suggestions in [9]).

\section{Comments irrelevant to the topic}

This is an annoying situation because, though the authors may refer to the editor, the latter might not be of great help and the authors still have to answer the reviewer's comment. In most cases, assuming the manuscript is well written, the reviewer's position might stem either from a quick reading of part of the manuscript or from an erroneous understanding or interpretation of a given section. Here, the authors should refrain from suggesting that the reviewer paid insufficient attention to the manuscript or inviting the reviewer to read again or more carefully the section under debate, but instead could make an effort to reformulate or enrich the whole idea or paragraph. Thus, the authors may answer: "To clarify the point, we have rewritten the whole paragraph as follows: ..."

\section{Checks for unlikely sources of biases}

This is undoubtedly an unpleasant query. The authors are confident in the theoretical foundations and/or model design and appropriateness and have already considered a sufficient number of sources of bias. Still, the authors are asked for more checks that feel useless. Here, diplomacy calls for...patience. Reexamine the theory and the model-building conditions and ask for the opinions of peers or external experts [10]. If something may be added to reassure the reviewer (more theory, more references, more calculations), then add it. Otherwise, take more time and place to present and support tactfully the authors' arguments without being dogmatic. This is somewhat time-consuming but should not be very demanding.

\section{Further developments of the authors' analyses}

Here too, consider seriously the relevance of the required developments with regard to the authors' chosen objective. If the authors sincerely feel that these developments would unnecessarily lengthen or complicate the manuscript, then express 


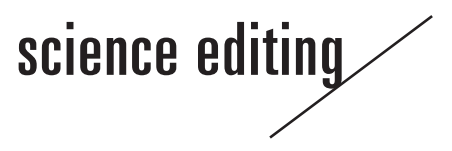

this response politely. Today, most journals limit the length of submitted manuscripts and insist that authors avoid dealing with several objectives within a single manuscript. Make these conditions the authors' main argument ("These developments are not within the scope of the current study...") and promise sincerely to deal with the required developments in future manuscripts in the same research field ("...these developments are underway and will be the object of future publications").

Redo the work on other hypotheses or with other methods This is something that most, if not all, authors would fiercely refuse, and for good reason-the submitted manuscript reflects the investment of time, money, and moral resources that would be difficult to repeat. If the authors feel that the query stems from a complete ignorance of the subject, that its sole reason might be the satisfaction of a reviewer's curiosity, or is abuse or vexation from an ill-intentioned opponent, then the authors may be "hard on the issue and soft on the person" [11]. Take two steps: first, answer by politely saying that the suggested hypothesis or method was not within your initial motives or foundations for carrying out the study; and second, discuss the issue separately with the editor $[8,10]$. Otherwise, inform the editor that the authors have decided to retract the submission because of a fundamental disagreement with one of the reviewers. It is very unlikely that the same query will come from another reviewer.

\section{The Editor's Role in Handling Reviewers' Comments}

Finally, remember that "You do not necessarily have to make every change suggested" $[5,12,13]$ and that "Referees are not gods (...). You are always entitled to disagree with a referee's criticism and not do what they suggest. In such cases though (...) make at least a token improvement to a criticized passage (...) to show that you have taken the criticism into account" [14]. In fact, editors do not always send back the revised manuscripts and the answers to the comments to the reviewers; instead, they might examine the revisions themselves and decide on the appropriateness of the amendments and the adequacy of the revised manuscript for the journal. Concurrently, serious reviewers that consider their task as a contribution to science would not put authors in any kind of dead-end but show they are keen to ensure some degree of completeness because perfection does not exist.

There were two opinions on "revise and resubmit." Shaw [6] said, "The craft of responding to reviewers effectively takes practice. It takes a great deal of effort, some creativity, and importantly, also the right attitude (...). What is important is that authors carefully manage the disagreement." Liu [10] wrote, "I frame the process of 'revise and resubmit' as an integrative negotiation where the authors collaborate with the reviewers and editors to reach a mutually agreeable outcome-a publishable manuscript (...). In most cases, the editorial review process involves a combination of complying with and persuading the reviewers and editors. I propose that we can apply strategies for integrative negotiation in the revision process to clarify and satisfy the needs of all parties-authors, reviewers, and editors-yielding a final version of the manuscript that represents an outcome better than any individual party's single contribution (...). Negotiation research teaches us that the combination of an open mind, cooperative spirit, optimism, and gratitude for the value added by others, results not only in tangible benefits for the manuscript itself, but also in profound learning experiences." [10].

\section{Conclusion}

Often, the answer to a scientific manuscript submission by an editorial office is "revise and resubmit." This decision is sometimes based on reviewers' comments that require difficult or long work and some other times on unnecessary, conflicting, or even irrelevant demands for extra material. The authors might then feel trapped and unable to provide convenient "point-by-point" answers to all reviewers' comments. Six patterns of reviewers' queries and authors' responses are presented in this essay. According to the above responses, carrying out an "integrative negotiation," showing "creativity," having the "right attitude," and "managing the disagreement" are components of diplomacy when handling these situations.

\section{Conflict of Interest}

No potential conflict of interest relevant to this article was reported.

\section{Funding}

The author received no financial support for this article.

\section{References}

1. Romero V. Getting published: revise and resubmit. Observer 2002 Sep 12 [Epub]. Available from: https://www. psychologicalscience.org/observer/getting-published-revise-and-resubmit

2. Luft HS. From the editors: perspectives on turnaround time. Health Serv Res 2004;39:1-6. https://doi.org/10.1111/ j.1475-6773.2004.00211.x

3. Nagel S. "Reject-and-resubmits": why we discontinued them 
at the JF [Internet]. Salt Lake City, UT: American Finance Association; 2018 [cited 2021 Sep 9]. Available from: https:// afajof.org/2018/03/reject-and-resubmits/

4. Card D, DellaVigna S. What do editors maximize? Evidence from four economics journals. Rev Econ Stat 2020;102:195-217. https://doi.org/10.1162/rest_a_00839

5. Klingner JK, Scanlon D, Pressley M. How to publish in scholarly journals. Educ Res 2005;34:14-20. https://doi. org/10.3102/0013189X034008014

6. Shaw JD. From the editors: responding to reviewers. Acad Manag J 2012;55:1261-3. https://doi.org/10.5465/amj. 2012.4006

7. Rindova V. Editor's comments: publishing theory when you are new to the game. Acad Manag Rev 2008;33:300-3. https://doi.org/10.5465/amr.2008.31193160

8. Cochran A. Should you "revise and resubmit"? [Internet]. The Scholarly Kitchen; 2016 [cited 2021 Sep 9]. Available from: https://scholarlykitchen.sspnet.org/2016/10/20/ should-you-revise-and-resubmit/

9. Rojon C, Saunders MN. Dealing with reviewers' comments in the publication process. Coach Int J Theory Res
Pract 2015;8:169-80. https://doi.org/10.1080/17521882.20 15.1047463

10. Liu LA. Addressing reviewer comments as an integrative negotiation. Manag Organ Rev 2014;10:183-90. https:// doi.org/10.1111/more.12061

11. Fisher R, Ury W, Patton B. Getting to yes: negotiating agreement without giving in. 3rd ed. New York, NY: Penguin; 2011.

12. Murnighan JK. Revising and resubmitting: author emotions, editor roles, and the value of dialogue. In: Frost PJ, Taylor MS, editors. Rhythms of academic life: personal accounts of careers in academia. Thousand Oaks, CA: Sage; 1996. p. 135-42.

13. Haspelmath M. Revise \& resubmit is damaging to science and should be abandoned [Internet]. Hypotheses; 2020 [cited 2021 Sep 9]. Available from: https://dlc.hypotheses. org/2333

14. McCarthy D. Revise and resubmit [Internet]. Hong Kong: David McCarthy; 2019 [cited 2021 Sep 9]. Available from: https://davidmccarthy.org/revise-and-resubmit/ 